\title{
DIFUSÃO INTERNACIONAL DE INOVAÇÃO: ESTUDO DE CASO EM UMA ORGANIZAÇÃO PÚBLICA
}

INTERNATIONAL DIFFUSION OF INNOVATION:

CASE STUDY IN A PUBLIC ORGANIZATION

\author{
Luciana Maines da Silva \\ Universidade do Vale do Rio dos Sinos, São Leopoldo, RS, Brasil. \\ E-mail: lucmasi@gmail.com \\ Paula Maines da Silva \\ Universidade do Vale do Rio dos Sinos, São Leopoldo, RS, Brasil. \\ E-mail:paulam@cpovo.net
}

Recebido em: 21.01.2017 - Aceito em: 18.03.2017

\section{RESUMO}

A participação do setor de serviços na geração de emprego da maioria dos países industriais vem crescendo nas últimas décadas. O setor também vem sendo reconhecido por sua produtividade e competitividade econômica, além de apresentar diversas inovações, difundidas também por outros setores da economia. Neste estudo, buscou-se identificar os elementos promotores da difusão da inovação no contexto de uma organização pública, utilizando, para isso, os elementos propostos por Rogers (2013). Assim, foi realizada pesquisa de cunho qualitativo, descritiva, através de estudo de caso único. Alguns dos elementos verificados que determinam a difusão da inovação na organização pública objeto do estudo são: (1) modelo de cartão bancário; (2) divulgação das inovações desenvolvidas; (3) difusão internacional; e (4) rede de relacionamento criada.

PALAVRAS-CHAVE: Inovação em serviço; Difusão da inovação; Difusão internacional; Organização pública; Banco público.

\section{ABSTRACT}

The service's sector participation in the employment of most of the industrial countries has been increasing in the last decades. It has also been recognized for its productivity and economic competitiveness, as well as the number of innovations, also spread by other sectors of the economy. In this study, we sought to identify the elements that promote the diffusion of innovation in the context of a public organization, trought the elements proposed by Rogers (2013). A qualitative, descriptive study was conducted through a single case study. Some of the elements verified that determine the diffusion of the innovation in the public organization object of the study are: (1) model of banking card; (2) dissemination of the 
innovations developed; (3) international diffusion; and (4) the network created.

KEYWORDS: Service innovation; Innovation diffusion; International diffusion; Public organization; Public bank.

\section{INTRODUÇÃO}

A discussão sobre inovação no setor público ainda é recente no Brasil e abre espaço para uma significativa agenda de pesquisas (Brandão e de Fátima BrunoFaria, 2012; Oliveira et al., 2015). Reconhecer a importância do setor público e os exemplos de inovação nesse ambiente é essencial para o desenvolvimento desse setor. Torna-se importante destacar que as iniciativas não se limitam à gestão ou a órgãos integralmente públicos. Os bancos públicos brasileiros não se enquadram na mesma dinâmica organizacional de outros órgãos do setor, uma vez que muitos são economias mistas e, além do viés social, precisam se manter competitivos no mercado. Considerado o total de ativos entre os bancos com atuação nacional, em 2015, Banco do Brasil (1 $1^{a}$ posição), a Caixa Econômica Federal ( $2^{\mathrm{a}}$ posição), o BNDES ( $3^{a}$ posição), o Banrisul (12 $2^{a}$ posição) e o Banco do Nordeste do Brasil (14 ${ }^{a}$ posição) estavam entre os vinte primeiros no ranking (Banco Central do Brasil, 2016). Sob esse argumento, torna-se pertinente avaliar os bancos como atores inseridos no setor de serviços. Soma-se a isso a importância desse setor nas economias nacional e mundial.

O setor de serviços vem crescendo nas últimas décadas e participa com a maior parte da oferta de empregos na maioria dos países industriais, sendo reconhecido por sua produtividade e competitividade econômica (Miles, 2005). O entendimento mais difundido é o de que serviço é o ato ou fornecimento que uma parte pode oferecer a outra, sendo totalmente intangível e não resultando na propriedade de algo (Kotler, 1982).

No Brasil, em 2014, o setor representou $60 \%$ do total do Produto Interno Bruto (PIB), que corresponde ao montante de $\mathrm{R} \$ 3.351,8$ bilhões. Dentro desse contexto, as atividades de intermediação financeira, seguros, previdência complementar e serviços relacionados participam com $9 \%$ no setor (IBGE, 2014). Outras atividades possuem participação maior, contudo o setor financeiro, principalmente o bancário, tem ampliado sua importância, uma vez que o Brasil está em quarto lugar em bancarização (Febraban, 2015), que é a concentração de recursos financeiros em bancos. Tal concentração de recursos exige, das instituições financeiras, capacidade robusta de processamento de dados e, principalmente, segurança nas transações. Além desses fatores, Gianiodis, Ettlie e Urbina (2014) reforçam 
que uma das formas de fortalecer o setor bancário se dá através da inovação em serviço, com o objetivo de desenvolver uma vantagem competitiva sustentável, concentrando-se na inovação de serviços, em vez da inovação tradicional, relacionada com instrumentos financeiros, como os derivados.

Muitas das inovações, principalmente no que tange à segurança da informação, são desenvolvidas pelas próprias instituições, e muitas dessas iniciativas são comunicadas e utilizadas por empresas do mesmo setor, em outros mercados. Essa utilização, ou difusão da inovação, é identificada quando uma ideia ou produto ganha impulso e se difunde através de uma população específica ou sistema social (Rogers, 2010).

A difusão da inovação no setor bancário é ratificada ao se afirmar que a inovação tem início a partir da adoção de um produto, processo ou novo sistema em determinado ambiente de negócios e se consolida através da difusão pelos usuários. Percebe-se a relação da inovação com o setor bancário, uma vez que, "por estar imerso num ambiente fortemente regulado, o setor bancário também apresenta inovações que surgem determinadas por leis e regulações" (Diniz, 2010, p. 411).

Percebendo a importância do setor de serviços e, principalmente, do setor público bancário, o presente artigo tem como objetivo identificar quais os elementos que determinam a difusão de iniciativas inovadoras em uma organização pública bancária. O avanço teórico se dará exatamente por se identificar elementos de difusão da inovação em organizações públicas, uma vez que não há estudos brasileiros nesse sentido. Com isso, pretende-se dar início a uma discussão sobre o tema.

Este artigo está estruturado com as seguintes subseções: inicialmente, apresenta-se uma revisão teórica embasada nos conceitos de difusão da inovação e inovação em serviços e na relação das tecnologias da informação com o setor bancário; após, são apresentados os procedimentos metodológicos utilizados para o desenvolvimento desta pesquisa, seguidos da contextualização dos resultados; na sequência, é apresentada uma discussão traçando a relação entre o caso e a teoria e, por fim, as principais conclusões a respeito do tema.

\section{REFERENCIAL TEÓRICO}

Ao longo dos anos, muitas inovações foram criadas, implementadas e difundidas. Contudo, grandes sistemas sociotécnicos complexos realizam mudanças somente de forma incremental (Bessant e Tidd, 2009). As inovações radicais acontecem, mas geralmente com início em nichos estratégicos, que podem se disseminar através de novos nichos de mercado, totalmente novos ou híbridos 
entre o nicho e o fluxo principal.

Rogers (2003), um dos principais autores que tratam da difusão da inovação, apresenta quatro principais elementos para a difusão, que são: a) inovação propriamente dita, que diz respeito às inovações tecnológicas e, principalmente, ao aspecto da reinvenção, ou seja, novos usos na adoção e difusão; b) canais de comunicação para a difusão, que são mais rápidos e eficientes como meio de informação aos interessados pela inovação; c) tempo, isto é, quanto tempo determinada inovação leva para ser divulgada e para que haja a persuasão, decisão, implementação e confirmação de seu uso; e d) sistema social, como elemento para a difusão, no que se refere à estrutura social, normas, papel dos tomadores de decisão, entre outros.

Uma mudança social ocorre sempre que uma nova ideia é inventada, difundida, adotada ou rejeitada. O termo "difusão" é utilizado tanto para a propagação espontânea e não planejada quanto para aquela dirigida. Importante salientar que a difusão é resultado da comunicação, enquanto a adoção ou rejeição dependem de decisão (Rogers, 2003). Dentro do conceito de difusão da inovação, Greenhalgh, Robert, Macfarlane, Bate e Kyriakidou (2004) distinguem a divulgação (difusão passiva), difusão (ativos e esforços planejados para persuadir grupos-alvo a adotar uma inovação), implementação (ativo e esforços planejados para integrar uma inovação dentro de uma organização) e sustentabilidade (tornando uma rotina de inovação até que ele atinja obsolescência).

As diversas influências que ajudam a espalhar a inovação podem ser entendidas como um continuum entre (1) difusão pura (em que a disseminação das inovações não é planejada, é informal, descentralizada e, em grande parte, horizontal ou mediada por pares) e (2) divulgação ativa (em que a propagação da inovação está prevista, é formal, muitas vezes centralizada e mais provável de ocorrer através de hierarquias verticais). Considerando que os meios de comunicação e outros canais impessoais podem criar a consciência de uma inovação, a influência interpessoal através de redes sociais é o mecanismo dominante para a difusão. Tais influências foram percebidas pelos pesquisadores ao realizarem uma revisão sistemática da difusão da inovação em organizações de serviço (Greenhalgh et al., 2004).

O setor de serviços vem sendo reconhecido como inovador e intensivo em conhecimento e tem sido apontado como vetor de inovação para outros setores da economia e como fonte de criação de valor (OECD, 2005; Käpylä et al, 2011). Contudo, nesse setor, o processo de inovação seria "exógeno e sua dinâmica, dependente das trajetórias de inovação industriais" (Vargas e Zawislak, 2007, p. 483).

Um processo dinâmico de inovação é aquele em que o ciclo do produto pode, 
de uma forma simplificada, ser caracterizado como progressão de um produto inovador através de um processo de inovação radial para um modelo mais incremental (Barras, 1990). Em pesquisa realizada sobre o setor financeiro, foram propostas seis grandes perspectivas para a revolução em serviço. Foi identificado que o ciclo da inovação prossegue desde o aumento da eficiência, através de melhorias na qualidade dos serviços, até a geração de novos produtos de serviços de rede. Esses serviços podem ser classificados como Serviços Intensivos em Conhecimento (SICs) ou Knowledge-Intensive Business Services (KIBS) (Barras, 1990).

Ao pesquisar o setor bancário, Barras (1990) ratifica a importância do setor e a relação da tecnologia com a inovação em serviço.

\section{MÉTODOS E PROCEDIMENTOS}

O presente artigo tem por objetivo identificar os elementos promotores da difusão da inovação no contexto de uma organização pública, utilizando, para isso, os elementos propostos por Rogers (2010). Para tanto, realizou-se uma pesquisa qualitativa, descritiva (Gil, 2010), através de estudo de caso único (Yin, 2001).

A coleta de dados se deu através de entrevistas em profundidade e análise de documentos primários. O produto, ou resultado da coleta, conduziu as autoras à análise de conteúdo, contemplando as seguintes etapas: (1) pré-análise; (2) exploração do material; e (3) tratamento dos resultados, inferência e interpretação (Bardin, 1977).

A seção a seguir apresenta a contextualização dos resultados.

\section{APRESENTAÇÃO E DISCUSSÃO DOS RESULTADOS}

O Banrisul é um banco múltiplo controlado pelo estado do Rio Grande do Sul e é líder no mercado regional. Importante destacar que é o único banco regional com atuação significativa e que concorre com bancos de maior porte, inclusive de âmbito global. Atualmente, é referência no setor brasileiro em tecnologia e segurança bancárias. O principal destaque refere-se ao uso do cartão inteligente. No mercado competitivo, o Banrisul ocupava, em dezembro de 2014 , a $11^{\text {a }}$ posição em ativos totais entre os bancos que compõem o Sistema Financeiro Nacional (SFN), $11^{\text {a }}$ posição em patrimônio líquido, sétima posição em depósitos totais e sétima em número de agências, excluído o BNDES, conforme ranking divulgado pelo Banco Central do Brasil (2016).

O banco foi pioneiro ao desenvolver tecnologia para o smartcard. Essa aplicação na verdade é mais conhecida como modelo ou padrão chamado MV (Mastercard Visa), que opera dentro do chip e serve para transações financeiras em ATMs (Automatic Teller Machine, ou caixa eletrônico), caixas ou POS (point 
of service, equipamentos eletrônicos). Qualquer cartão que pertença a qualquer banco no mundo e que contenha chip possui o padrão MV. O Banrisul, em vez de comprar ou adquirir qualquer solução, desenvolveu o sistema internamente, usando o padrão americano, que é totalmente compatível com o padrão mundial. Além disso, o banco desenvolveu também uma aplicação de cidadania - conhecida como padrão $\mathrm{BKI}$, que serve para transações financeiras, transações de segurança, ligadas à cidadania - , conhecida como certificação digital. O Banrisul foi adiante, sendo o primeiro banco a colocar dentro de um cartão bancário um e-cpf, padrão atualmente adotado pelo governo brasileiro, que é o padrão do ICP Brasil - autoridade certificadora nacional. Importante ressaltar que o Brasil possui uma infraestrutura de chaves públicas - a ICP Brasil -, que está sediada numa autarquia da Casa Civil da Presidência da República, no Instituto Nacional de Tecnologia da Informação (ITI). A Receita Federal e o Judiciário fazem uso desse certificado digital. Percebe-se aqui conexão entre a inovação desenvolvida pelo Banrisul e os tipos de inovação propostos por Schumpeter (1912). O banco busca, através do desenvolvimento de novos serviços, a abertura de um novo mercado.

O desenvolvimento de soluções em segurança da informação, assim como outras não tratadas neste artigo, foi realizado internamente, por uma decisão da alta gestão de buscar novas frentes e estar um passo à frente do modelo nacional, principalmente em relação a outros bancos. Poucos recursos de terceiros são utilizados eventualmente, dando prioridade para o desenvolvimento com equipe própria. O Banrisul possui uma área de Pesquisa e Desenvolvimento (P\&D), contudo esta não é explícita. O desenvolvimento de novos produtos é discutido em reuniões para posterior execução, mas os envolvidos dividem seu tempo com outras funções. Com isso, o banco não conta com orçamento específico para P\&D, precisando dividir o orçamento geral das unidades de Tecnologia da Informação (TI). Porém, tanto o aspecto orçamentário como a estruturação da área de P\&D são ações que a diretoria pretende implantar em breve.

O banco não possui registro de patente dessas soluções e isso é apontado como um "grande erro" por parte do diretor de TI, uma vez que elas podem ser copiadas. Contudo, o plano é que, futuramente, todas as inovações que sejam desenvolvidas possam ser patenteadas. Um exemplo que esclarece essa necessidade é a própria aplicação MV. O chip utilizado nos cartões do Banrisul é fabricado na Alemanha, por uma empresa que, ao desenvolver os chips, já aplica uma camada de sistemas operacionais (SOs) para aplicação mundial. Um desses sistemas é o do Banrisul, que está em chips de cartões ao redor do mundo. Para sua utilização, 
basta o contato com a Visa Master, mas o banco nunca fez uso dessa solução para comercialização, e o registro de patente auxiliaria nessa comercialização. O maior impeditivo é a falta de foco comercial nas operações da área de $\mathrm{TI}$, pois atualmente o setor concorre com a gestão de produtos e serviços diretamente voltados ao setor bancário. Contudo, o não patenteamento tem vantagens, como apontado por Bessant e Tidd (2009, p. 233), quando afirmam que, muitas vezes, o "patenteamento tende a ocorrer cedo, em um processo de desenvolvimento, e, como consequência, pode não dizer nada sobre o potencial econômico ou comercial de inovação".

A direção de TI foi a principal responsável por divulgar as ações do Banrisul, nessa área, para fora do país. Em um primeiro momento, a divulgação se deu no cenário nacional. A visão é a de que, mesmo sendo um banco de porte menor, de âmbito regional, o banco deve estar no mesmo nível dos demais concorrentes do mercado. O desafio é mostrar que, apesar de ser regional, deve ter posicionamento internacional no que tange a tecnologia. Para esse fim, a principal deficiência percebida é o domínio da língua inglesa pelos empregados, o que dificulta essa divulgação no mercado global. O Banrisul já avançou ao apresentar seu relatório de Relação com Investidores em inglês, possibilitando que empresas e governos de qualquer país conheçam a instituição.

Ao lançar seu produto Banricompras, criou uma rede de adquirência, atualmente denominada Vero. Com o passar dos anos, o banco entendeu a necessidade de aceitar outras bandeiras na rede de adquirência, com o intuito de ampliar sua participação no mercado. Atualmente, a Vero concorre com redes como a Cielo (Cielo, 2015). Para que as bandeiras Visa e Master pudessem ser utilizadas nos equipamentos, era necessária a obtenção de Certificação $\mathrm{PCl}$, emitida pelo $\mathrm{PCl}$ Security Standards Council, um fórum aberto global para contínuo desenvolvimento, aprimoramento, armazenamento, disseminação e implementação de padrões de segurança para a proteção de dados de contas. Esse conselho tem como missão aprimorar a segurança de dados de contas de pagamento, promovendo a educação e a conscientização sobre os Padrões de Segurança PCI (PCI, 2015).

O Banrisul foi um dos primeiros a sofrer uma auditoria e estar totalmente adequado ao processo. Importante salientar que o conselho mundial do $\mathrm{PCl}$ é composto por 41 membros, que decidem as regras do $\mathrm{PCI}$ no mundo. O Banrisul foi o primeiro membro latino-americano a fazer parte desse quadro (no período de 2009 a 2012). Isso significa dizer que a regra aplicada atualmente foi escrita em parte pelo banco, o que facilitou, posteriormente, sua certificação.

A ampliação da utilização do sistema dos cartões foi um dos desafios en- 
contrados pelo Banrisul. Além do mercado nacional, através da associação com a Smartcard Lines Latin América, alguns países estrangeiros manifestaram interesse. A Costa Rica atualmente está importando a solução para aplicação em seu modelo nacional. O país, através de seu Banco Central e governo, vai utilizar a solução bancária e de cidadania. O México também demonstrou interesse, e as negociações estão em andamento. A perspectiva é de que a solução atinja outros países da América Latina. Essa difusão se relaciona ao pensamento de Tigre (2009), que destaca que tecnologias da informação permitem uma crescente codificação do conhecimento, representando uma janela de oportunidade para sua difusão internacional.

A solução também gerou um convite, por meio da Federação Brasileira de Bancos (Febraban), para apresentá-la à agência de comércio dos Estados Unidos (USTDA). A missão nos Estados Unidos visitou o Vale do Silício (Califórnia), Washington e Nova York, culminando com uma reunião com o governo americano. O objetivo da reunião era discutir as tecnologias de segurança bancária, uma vez que o modelo brasileiro está muito acima do que os americanos, até então, conheciam. Contudo, a utilização da aplicação no mercado norte-americano é difícil, pois o conceito de chave pública utilizado pelos Estados Unidos é diferente do conceito brasileiro. O Brasil está mais ligado ao modelo europeu, sobre o qual muitas informações estão sendo trocadas. Portugal é um exemplo de país que está buscando informações sobre a Certificação PCl. A dificuldade da aplicação nos Estados Unidos corrobora as barreiras de utilização das inovações propostas por Bessant e Tidd (2009), que apontam a estrutura como um desses obstáculos.

Outro exemplo de divulgação das ações e iniciativas inovadoras do Banrisul foi a participação, em 2014, no China International Software and Information Service Forum \& Entrepreneurs's Summit 2014 (CISIS 2014), representado pelo seu então superintendente de TI. No evento, foi apresentado o artigo "A aplicação de tecnologias de segurança já comprovadas para a internet das coisas". A ideia para o artigo surgiu durante um dos fóruns internacionais de TI, organizado pelo Banrisul, que tinha o objetivo de mostrar que o que é desenvolvido nos bancos (Banrisul) pode ser aplicado nas novas ondas (por exemplo, a internet das coisas - internet of things - loT).

Por fim, a realização de um fórum específico para a discussão de assuntos de TI foi outra forma encontrada pelo Banrisul para, além de estimular a discussão, apresentar seus projetos. Em 2008, foi realizado o primeiro Fórum Internacional de TI, que teve por objetivo "discutir as tendências de mercado, explorando os diversos aspectos e visões de temas contemporâneos de grande importância" (Fórum Internacional de TI Banrisul, 2015). Nesse ambiente, diferentes áreas, representadas por especialistas 
nacionais e internacionais, discutiram o presente e o futuro que conduzem a predominância do mercado e perspectivas para bancos, grandes empresas e governos.

Assim, percebe-se que o banco cria, constantemente, esforços planejados para ampliar seu público-alvo e adotar iniciativas inovadoras. Conforme apresentado no referencial teórico, Roger (2013) apresenta quatro principais elementos para a difusão da inovação. Ao avaliar o caso, verificou-se que o banco investe fortemente em novos serviços, principalmente naqueles voltados ao uso do cartão inteligente (smartcard). O Banrisul desenvolveu um modelo de cartão bancário para operações financeiras e, no mesmo cartão, uma operação de cidadania de certificação digital de segurança. A utilização do modelo de cartão para dois fins, basicamente distintos, corrobora a proposição de Roger (2013), qual seja, a da inovação tecnológica, especificamente no que tange a novos usos na adoção.

O segundo elemento, os canais de comunicação, relaciona-se à constatação de que o Banrisul não mede esforços na divulgação de suas inovações. A partir de ampla divulgação interna (âmbito nacional), diversos convites surgiram para participação em fóruns de discussão em ambiente global e missões de divulgação e troca de experiências. A organização do Fórum Internacional de TI também é uma forma efetiva de disseminar o que vem sendo feito pelo banco, assim como comparar a solução desenvolvida com outras práticas.

O terceiro elemento proposto por Rogers (2013) é o tempo decorrido entre a divulgação da inovação e sua implementação e confirmação de seu uso. Verificouse que, no caso do Banrisul, a inovação já está sendo implantada pelo governo da Costa Rica. Contudo, não se explorou suficientemente na entrevista esse quesito.

O último elemento apontado pelo autor é o emprego do sistema social para a difusão da inovação. Percebeu-se que a rede de relacionamento criada, inicialmente, através da Febraban e, posteriormente, através de novas conexões faz com que as inovações sejam divulgadas e discutidas, como foi o caso da apresentação no CISIS 2014.

No que tange à difusão internacional da inovação, a dificuldade da aplicação nos Estados Unidos confirma a existência de barreiras na utilização das inovações, o que é mencionado por Bessant e Tidd (2009), que apontam a estrutura como uma dessas dificuldades.

Já a organização do Fórum Internacional de TI e a busca pela disseminação de conhecimento podem ser relacionadas com uma das proposições de Schumpeter (1912), a de que o desenvolvimento só é obtido através de novas combinações.

Por fim, ao considerar a diferença de nível da difusão proposta por Gree- 
nhalgh et al. (2004), fica evidente que o Banrisul difunde suas soluções, uma vez que os autores consideram, para tal, a mobilização de ativos e esforços planejados para persuadir grupos-alvo a adotar uma inovação.

\section{CONSIDERAÇÕES FINAIS}

O presente artigo buscou identificar quais os elementos que determinam a difusão de iniciativas inovadoras de organização pública do setor bancário brasileiro. Os principais elementos para a difusão, propostos por Rogers (2013), embasaram esta pesquisa. Sua aplicação se deu em uma empresa do setor bancário, o Banrisul, que atualmente é um dos cinco bancos regionais ainda em operação no Brasil e que, apesar de seu porte, concorre fortemente, nos mercados onde atua, com grandes instituições nacionais e internacionais.

Dos três elementos propostos, somente o tempo não foi devidamente explorado. Os demais podem ser claramente percebidos. Contudo, as iniciativas inovadoras do Banrisul ainda não são amplamente utilizadas. Dentro do conceito de difusão da inovação proposto por Greenhalgh et al. (2004), o banco contempla as etapas de divulgação e difusão. Porém, novos esforços são necessários para atingir a ampla implementação e sustentabilidade. Mas é importante destacar que são poucos os casos de inovação em serviço desenvolvidos no setor público que perpassam barreiras na utilização. Assim, o presente caso serve de exemplo de que é possível ultrapassar essas barreiras, inclusive com iniciativa inovadora difundida internacionalmente.

Apesar da identificação dos fatores que determinam a inovação no setor bancário, este estudo apresentou algumas limitações. Por se tratar de estudo de caso único, não é possível garantir que os elementos identificados que determinam a difusão da inovação sejam utilizados por outras organizações públicas. Sugere-se, assim, que novas pesquisas sejam realizadas com outras organizações, buscando identificar se há um padrão nos elementos de difusão. Também, a comparação com elementos de outros setores, relacionados à tecnologia, pode trazer novos aspectos que contribuam para a disseminação sistemática de iniciativas inovadoras.

\section{REFERÊNCIAS}


Banco Central do Brasil. (2016). IF Data. Recuperado de https://www3.bcb. gov.br/informes/?wicket:interface=:0:3:::

Banrisul. Relação com investidores. Recuperado de http://ri.banrisul.com.br/ banrisul/web/default_pt.asp?idioma $=0 \&$ conta $=28$

Banrisul. (s/data) Apresentação interna sobre a CISIS 2014.

Bardin, L. (1977). Análise de conteúdo. Lisboa: Edições 70, 225.

Barras, R. (1990). Interactive innovation in financial and business services: the vanguard of the service revolution. Research policy, 19(3), 215-237.

Bessant, J., \& Tidd, J. (2009). Inovação e empreendedorismo: Administração. Porto Alegre: Bookman.

Brandão, S. M., \& de Fátima Bruno-Faria, M. (2013). Inovação no setor público: análise da produção científica em periódicos nacionais e internacionais da área de administração. Revista de Administração Pública, 47(1), 227-248.

Cielo. (2015). Sítio institucional. Recuperado de https://www.cielo.com.br/conheca.

Diniz, E. H. (2010). Determinantes de inovação no setor bancário. In Fonseca, C. E. C. D., Meirelles, F. D. S., \& Diniz, E. H. Tecnologia bancária no Brasil: Uma história de conquistas, uma visão de futuro (p. 410-417). São Paulo: FGVRAE.

Febraban. (2014). Pesquisa FEBRABAN de Tecnologia Bancária 2013. Recuperado de http://www.Febraban.org.br/7Rof7SWg6qmyvwJcFwF7I0aSDf9jyV/siteFebraban/Pesquisa\%20FEBRABAN\%20de\%20Tecnologia\%20Banc\%E1ria\%202013.pdf

Febraban. (2015). Pesquisa FEBRABAN de Tecnologia Bancária 2014. Recuperado de http://www.Febraban.org.br/7Rof7SWg6qmyvwJcFwF7I0aSDf9jyV/siteFebraban/Pesquisa\%20FEBRABAN\%20de\%20Tecnologia\%20Banc\%E1ria\%20-\%202014\%20\%282\%29.pdf

Fórum Internacional de TI Banrisul. 2015. Recuperado de http://www.forumtibanrisul.com.br/index.php

Gallouj, F. (1998). Innovating in reverse: services and the reverse product cycle. European Journal of Innovation Management, 1(3), 123-138.

Gianiodis, P. T., Ettlie, J. E., \& Urbina, J. J. (2014). Open service innovation in the global banking industry: Inside-out versus outside-in strategies. The Academy of Management Perspectives, 28(1), 76-91.

Gil, A. C. (2010). Métodos e técnicas de pesquisa social. In Métodos e técnicas de pesquisa social. São Paulo: Atlas.

Greenhalgh, T., Robert, G., Macfarlane, F., Bate, P., \& Kyriakidou, O. (2004). Dif- 
fusion of innovations in service organizations: systematic review and recommendations. Milbank Quarterly, 82(4), 581-629.

IBGE. Contas Nacionais Trimestrais. Recuperado de ftp://ftp.ibge.gov.br/Contas_ Nacionais/Contas_Nacionais_Trimestrais/Fasciculo_Indicadores_IBGE/pibvol-val_201404caderno.pdf

Käpylä, J., Laihonen, H., Lönnqvist, A., \& Carlucci, D. (2011). Knowledge-intensity as an organisational characteristic. Knowledge Management Research \& Practice, 9(4), 315-326.

Kotler, P. (1982). Marketing for nonprofit organizations. Englewood Cliffs, New Jersey: Prentice-Hall.

Miles, I. Innovation in Services. In Fagerberg, J. (2005). The Oxford handbook of innovation (p. 433-458). Oxford: Oxford University Press.

OECD. (2005). Science, technology and industry scoreboard 2005. Paris: OECD.

PCI. (2015). PCI Security Standards Council. Recuperado de https://pt.pcisecuritystandards.org/minisite/en/

Oliveira, A. N., de Freitas Carneiro, A., do Nascimento Cidade-Konzen, I. G., \& da Silva Neto, J. M. (2015). O que se discute sobre Inovação no Setor Público Brasileiro: Análise do período entre 2000 (pós LRF) e 2014. Revista de Estudos Sociais, 17(35), 216-237.

Rogers, E. M. (2010). Diffusion of innovations. Nova York: Simon and Schuster.

Schumpeter, J. A. (1961). Teoria do desenvolvimento econômico. Rio de Janeiro: Fundo de Cultura. Primeira edição: 1912.

Tigre, P. B. (2009, janeiro/junho). Paradigmas tecnológicos e teorias econômicas da firma. Revista Brasileira de Inovação, 4(1), 187-223.

Vargas, E. R., \& Zawislak, P. A. (2007). A dinâmica da inovação em serviços hospitalares. Inovação em serviços intensivos em conhecimento, 1, 483-502.

Yin, R. K. (2001). Estudo de Caso: Planejamento e métodos. Porto Alegre: Bookman. 